\title{
Comparison of Performance Records and National Breeding Values as Input into International Genetic Evaluation
}

\author{
W. F. Fikse \\ Interbull Centre, Department of Animal Breeding and Genetics, \\ Swedish University of Agricultural Sciences, S-750 07, Uppsala, Sweden
}

\begin{abstract}
The purpose of this investigation was to compare accuracy and precision of variance components and breeding values for international genetic evaluations based on national breeding values or animal performance records. A conventional progeny test scheme was simulated for 3 countries. True breeding values and observations were generated specific to production environments. Two production environments were considered, and both balanced and unbalanced distribution of production environments over countries were considered. True breeding values for both production environments were generated as bivariate normal deviates, and low (0.70) and high (0.90) genetic correlations between performance in production environments were considered. Each cow had an observation in one country only. Performance records were generated as the sum of the true breeding value, a contemporary group effect, and a random residual. Eight generations of data were simulated, and the entire simulated data set was used to compare 3 methods for international genetic evaluation: 1) multiple-trait across-country evaluation based on national predicted breeding values of bulls (MACE), 2) international genetic evaluation across country using performance records, and 3) international genetic evaluation across production environment using performance records. Estimated genetic parameters were biased for all models in this study. Genetic correlations between countries were generally more biased for MACE than for the across-country analyses using performance records. Bias in within-country genetic variances was smaller for MACE. Even genetic parameters obtained with the international evaluation across production environment using performance records were biased, despite the fact that this model was closest to the true, simulated model. The root mean square error of predicted breeding values was similar between models for most of the situations considered. The difference be-
\end{abstract}

Received August 6, 2002.

Accepted February 3, 2004.

Corresponding author: W. F. Fikse; e-mail: Freddy.Fikse@hgen. slu.se. tween models was largest when the distribution of production environments over countries was unbalanced and the genetic correlation between performance in production environments was low (0.70). Using breeding values obtained with the across-production environment international genetic evaluation based on performance records will increase the response to selection. (Key words: simulation, borderless evaluation, multiple-trait across-country evaluation)

Abbreviation key: GaMcou = international evaluation on country basis using performance records, GAMenv = international evaluation on production environment basis using performance records, MACE $=$ multiple-trait across-country evaluation, NAMcou $=$ national evaluation using performance records, $\mathbf{P B V}=$ predicted breeding value, $\mathbf{R M S E}=$ root mean square error, $\mathbf{T B V}=$ true breeding value.

\section{INTRODUCTION}

Genetic improvement and genetic evaluation programs for dairy cattle have been primarily organized within country. However, a more recent development is the growing importance of international links between breeding programs (McGuirk, 1998). Selecting bulls across countries can enhance genetic progress considerably when countries have similar or identical breeding goals (Banos and Smith, 1991). To realize this progress, breeding value predictions should be similar in all countries. Differences in genetic evaluation systems influence genetic correlations between countries (e.g., Banos et al., 1992; Emanuelson et al., 1999) and may hamper genetic progress (Lohuis and Dekkers, 1998). Therefore, Lohuis and Dekkers (1998) suggested consideration of borderless evaluations that standardize data collection and evaluation across borders and in which traits are based on production environments instead of country boundaries.

Weigel and Rekaya (2000) and Zwald et al. (2001), both working with field data, clustered herds across country borders according to information on production systems. The lowest genetic correlation between performance in production environments was 0.81 (Weigel 
and Rekaya, 2000) and 0.59 (Zwald et al., 2001), indicating the presence of genotype $\times$ environment interaction. Furthermore, the number of production environments was smaller than the number of countries, and boundaries of production environments and countries did not overlap perfectly.

Consequences of similar situations as described before for the optimum design of breeding programs and genetic improvement were investigated by Banos and Smith (1991) and Lohuis and Dekkers (1998), using deterministic simulations. However, little is known about the gain in precision of predicted breeding values (PBV) when international genetic evaluations are borderless. The aim of this study was to investigate gain in precision and accuracy of estimated variance components and predicted genetic merit when individual performance records can be used instead of national breeding values and when international evaluation is across production environment rather than country.

\section{MATERIALS AND METHODS}

Three countries and 2 production environments were simulated. Animals were generated within country, and observations were within production environment. That is, the breeding programs were run within countries, but true breeding values (TBV) and observations were generated specific to production environments. Performance in each production environment was treated as a separate biological trait. Unit of time was generation, and 8 discrete generations were simulated in addition to an unselected base generation. The simulation was repeated 15 times. Generated data were subsequently used as input to 3 different methods of international genetic evaluation.

\section{Simulation of Data}

The breeding program was a conventional progeny test scheme. Countries $\mathrm{A}$ and $\mathrm{C}$ were of equal size and comprised 20,000 cows per generation. Country B had only one-half as many cows per generation. In each generation, 200 young bulls were progeny-tested in countries $\mathrm{A}$ and $\mathrm{C}$ and 100 bulls were progeny-tested in country B, of which the best 10 and 5\%, respectively, were used as proven bulls and sire of sons in the next generation. Progeny group size for young bulls was normally distributed around a mean of $80(\mathrm{SD}=5)$. Proven bulls that had passed the progeny test received an additional 200 progeny in the next generation. One hundred elite dams in countries $\mathrm{A}$ and $\mathrm{C}$ and 50 elite dams in country B were selected as dams of sons, and each elite dam was mated to one sire of sons to produce 2 full brothers. Each cow was mated to either a proven or a
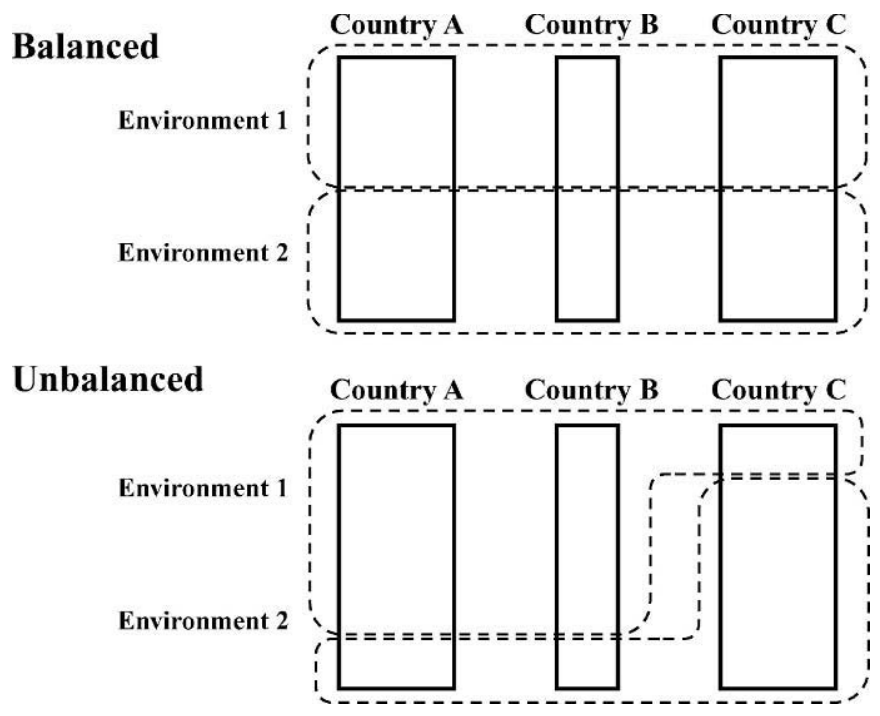

Figure 1. Distribution of production environments over countries.

young bull to produce one female offspring for the next generation. Mating of selected animals was random.

Selection of animals to produce the next generation was done within country, regardless of production environment. The criterion for selection was national breeding values predicted within country. Sires of sons and proven bulls that had been selected within country were exchanged from generation 3 forward. Country B imported 30 and $20 \%$ male genetic material from countries $\mathrm{A}$ and $\mathrm{C}$, respectively. Each of countries A and C imported $25 \%$ male genetic material from the other.

Two different distributions of environments over countries were considered (Figure 1). In the first situation (balanced), $50 \%$ of the observations in each country were made in each production environment. In the second situation (unbalanced), $90 \%$ of the observations in countries A and B and $10 \%$ of the observations in country $\mathrm{C}$ were made in the first production environment.

Performance in production environments was treated as genetically distinct, although correlated, traits. True breeding values for first lactation production in both production environments were generated as the sum of the parent average and a Mendelian sampling deviation. This Mendelian sampling deviation was drawn from a multivariate normal distribution and reflected the genetic covariance structure among both traits as well as the inbreeding coefficients of the parents (Fikse and Banos, 2001). Genetic variance and heritability were 210 and 0.30 , respectively, for both traits. Genetic correlation between performance in both production environments was 0.70 or 0.90 .

Observations were generated as the sum of a contemporary group effect, the TBV and a residual. Contempo- 
rary group size was, on average, $20(\mathrm{SD}=5)$ with a minimum size of 5 . Contemporary group effects were drawn from a normal distribution with mean zero and variance equal to $10 \%$ of the total phenotypic variance. Contemporary groups were nested within country and production environment. Cows were assigned to contemporary groups such that daughter-dam pairs were likely to produce in the same production environment.

Breeding values were predicted for each country separately in each generation after observations had been generated. A model was used that included fixed contemporary and genetic group effects as well as a random animal effect. Genetic groups for phantom parents (of base animals and imported animals) were formed on the bases of country of origin and generation of birth. Simulated variance components were used in the national genetic evaluation. The mixed model equations for breeding value prediction were set up according to the implicit representation method, which reduces memory requirements by taking advantage of the occurrence of repeated blocks in the equation system (Tier and Graser, 1991). The mixed model equations were solved with a pre-condition conjugate gradient algorithm (Strandén and Lidauer, 1999). The pre-conditioner matrix was block diagonal, and, for fixed effects, the complete diagonal block of the left hand side of the mixed models equations was used. For animals, the diagonal blocks pertaining to all equations of an animal were used. Solutions of the mixed model equations were assumed converged when the average relative difference between consecutive rounds was $<10^{-6}$.

\section{International Genetic Evaluation}

At the end of the last generation, the complete set of generated data was used to compare 3 methods for international genetic evaluations:

Multiple-trait across-country evaluation. A 2step procedure was used to obtain breeding values with a multiple-trait across-country evaluation (MACE) (Figure 2). First, national breeding values were predicted separately for all 3 countries. Next, national breeding values for sires were de-regressed and used in an acrosscountry evaluation that treated performance in each country as separate traits.

National breeding values were predicted using performance records for all animals using an animal model (NAmcou) that included fixed contemporary and genetic group effects. This model was similar to the national genetic evaluation model described in the Simulation of Data section:

$$
y_{i j}=c g_{i}+\sum_{m=1}^{M} q_{j m} g_{m}+a_{j}+e_{i j}
$$

where $y_{i j}$ is the observation on animal $j$ in contemporary group $\mathrm{i}$; $\mathrm{cg}_{\mathrm{i}}$ is the fixed effect of contemporary group $\mathrm{i}$; $a_{j}$ is the random additive genetic effect of animal $j$ (a $\sim N\left(\mathbf{0}, \mathbf{A} \sigma_{\mathbf{a}}^{2}\right)$, where $\mathbf{A}$ is the additive genetic relationship matrix for all animals based on sire and dam relationships, and $\sigma_{a}^{2}$ is the additive genetic variance); $\mathrm{q}_{j m}$ is the contribution of group $m$ to the genetic merit of animal $j ; g_{m}$ is the fixed effect of group $\mathrm{m} ; \mathrm{M}$ is the number of groups; and $\mathrm{e}_{\mathrm{ij}}$ is the random residual $\left(\mathbf{e} \sim N\left(\mathbf{0}, \mathbf{I} \sigma_{\mathrm{e}}^{2}\right)\right.$, where $\sigma_{\mathrm{e}}^{2}$ is the residual variance). The mixed model equations were solved with the pre-condition conjugate gradient algorithm described previously.

Estimated variance components were used and were obtained with a similar model as for prediction of breeding values, except that sire instead of animal was used as the genetic effect. A sire model was used for estimation of variance components for computational reasons. The AI-REML implementation in the DMU software package (Jensen et al., 1997) was used. Estimates of variance components were assumed converged when the norm of the gradient of the parameter vector was $<10^{-4}$.

De-regressed national breeding values for sires were analyzed with a multiple-trait model containing fixed country mean effects and random genetic group and sire effects (Schaeffer, 1994):

$$
z_{i j}=\mu_{i}+\sum_{m_{=1}}^{M} q_{i j m} g_{i m}+s_{i j}+\varepsilon_{i j}
$$

where $z_{i j}$ is the de-regressed national breeding value for sire $j$ in county $i$; $\mu_{i}$ is the fixed effect of country $i$; $g_{i m}$ is the random effect of group $m$ in country $i$ ( $\mathbf{g}$ $N\left(\mathbf{0}, \mathbf{I} \otimes \mathbf{G}_{\mathrm{s}}\right)$, where $\mathbf{G}_{\mathrm{s}}$ contains the sire variances and covariances among countries); $\mathrm{s}_{\mathrm{ij}}$ is the random additive genetic effect of sire $\mathrm{j}$ in country $\mathrm{i}\left(\mathbf{s} \sim N\left(\mathbf{0}, \mathbf{A}_{\mathrm{s}} \otimes \mathbf{G}_{\mathrm{s}}\right)\right.$, where $\mathbf{A}_{\mathrm{s}}$ is the additive genetic relationship matrix for all bulls based on sire and maternal grandsire relationships); and $\varepsilon_{\mathrm{ij}}$ is the random residual $(\varepsilon \sim N(\mathbf{0}$, $\sum^{+} \mathbf{D}_{i} \sigma_{\varepsilon_{i}}^{2}$, where $\mathbf{D}_{\mathbf{i}}$ is a diagonal matrix with weighting factors (Fikse and Banos, 2001) as elements, and $\sigma_{\varepsilon_{i}}^{2}$ is the residual variance for country i). Genetic groups for unknown parents were defined according to country of origin, generation, and path of selection. Solutions to the MACE mixed model equations were obtained with a Gauss-Seidel iteration on data algorithm.

National breeding values were de-regressed within country (Jairath et al., 1998). Sire variances were estimated within country with an EM-REML algorithm (Sullivan, 1999). Genetic correlations were also esti- 


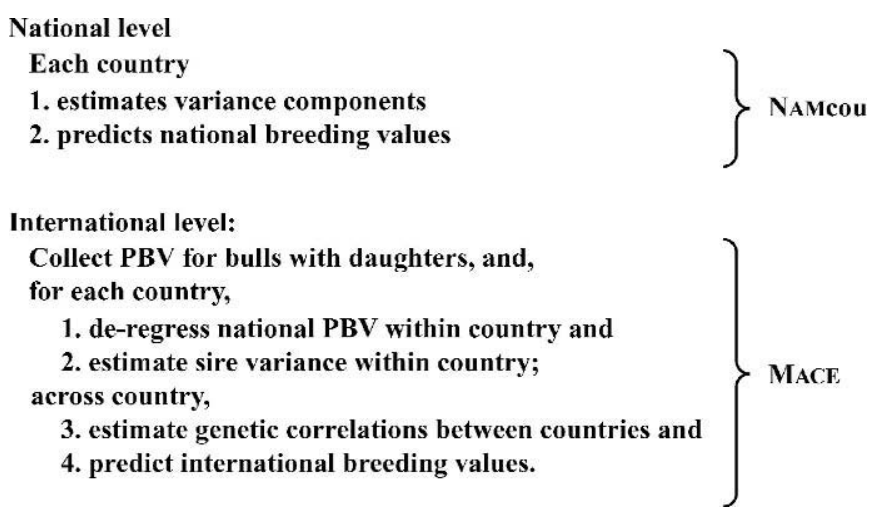

Figure 2. Illustration of the process to obtain international breeding values with multiple-trait across-country evalutions $($ MACE $)$. NAMcou $=$ national evalution using performance records; PBV = predicted breeding value.

mated with EM-REML, using a well-connected subset of the data (Sigurdsson et al., 1996). This subset contained data from full-sib families whose members had daughters in multiple countries, similar to the current Interbull practice.

Breeding values for cows on country scales other than the country of origin were computed using conversion equations. Conversion equations were computed from MACE breeding values as a linear regression of international breeding values in the 'importing' country on breeding values in the 'exporting' country. The MACE breeding values for bulls that originated in the 'exporting' country were used to estimate regression coefficients.

International evaluation on country basis using performance records. Performance records were analyzed with a 3 -trait model, where countries were treated as separate, although correlated, traits:

$$
y_{i j k}=c g_{i}+a_{j k}+e_{i j k},
$$

where $\mathrm{y}_{\mathrm{ijk}}$ is the observation on animal $\mathrm{j}$ in country $\mathrm{k}$ and contemporary group $i ; a_{j k}$ is the random additive genetic effect of animal $\mathrm{j}$ in country $\mathrm{k}\left(\mathbf{a} \sim N\left(\mathbf{0}, \mathbf{A} \otimes \mathbf{G}_{\mathrm{c}}\right)\right.$, where $\mathbf{G}_{\mathrm{c}}$ contains the genetic variances and covariances among countries); and $\mathrm{e}_{\mathrm{ijk}}$ is the random residual $\left(\mathbf{e} \sim N\left(\mathbf{0}, \sum^{+} \mathbf{I} \sigma_{e_{\mathrm{k}}}^{2}\right)\right.$, where $\sigma_{e_{\mathrm{k}}}^{2}$ is the residual variance for country k). Variance components were estimated from the data with a similar model, except that sire was used as random effect instead of animal. The procedures to estimate variance components and predict breeding values were the same as for the national genetic evaluation.

International evaluation on production environment basis using performance records. Performance records were analyzed with a bi-variate model, where production environments were treated as separate, although correlated, traits:

$$
y_{i j l}=c g_{i}+a_{j l}+e_{i j l}
$$

where $y_{i j l}$ is the observation on animal $\mathrm{j}$ in production environment $l$ and contemporary group $i$; $a_{j 1}$ is the random additive genetic effect of animal $j$ in production environment $1\left(\mathbf{a} \sim N\left(\mathbf{0}, \mathbf{A} \otimes \mathbf{G}_{\mathrm{p}}\right)\right.$, where $\mathrm{G}_{\mathrm{p}}$ contains the genetic variances and covariances among production environments); and $\mathrm{e}_{\mathrm{ijl}}$ is the random residual $(\mathbf{e} \sim N(\mathbf{0}$, $\sum^{+} \mathbf{I} \sigma_{e_{\mathrm{i}}}^{2}$, where $\sigma_{e_{\mathrm{i}}}^{2}$ is the residual variance for production environment 1). Estimated variance components and PBV were obtained in a similar way as for the international evaluation on country basis using performance records (GAMcou).

\section{Comparisons and Statistics}

Bias and root mean square error (RMSE) for estimated variance components were computed for all 3 international genetic evaluation methods. True breeding values were simulated for each production environment; thus, variance components and TBV for each country were not available and had to be calculated (Table 1). True breeding values specific to each country were obtained by weighting TBV for each production environment by the proportion of herds belonging to this production environment. The true genetic variance for each country and the true genetic correlations between countries were computed as the variance $(\times 2)$ and correlation between Mendelian sampling deviations for each country. Mendelian sampling deviations on each country scale were for each animal calculated as the difference between the TBV and the parent average.

The 3 methods were also compared based on the bias and RMSE of PBV on each country and production envi- 
Table 1. True genetic variance within countries (diagonal) and genetic correlations between countries (offdiagonal) for balanced and unbalanced distribution of 2 production environments and 2 levels of genetic correlation (rG) between production environments.

\begin{tabular}{|c|c|c|c|c|c|c|c|}
\hline \multirow[b]{2}{*}{$\mathrm{rG}$} & \multirow[b]{2}{*}{ Country } & \multicolumn{3}{|c|}{ Balanced } & \multicolumn{3}{|c|}{ Unbalanced } \\
\hline & & Country A & Country B & Country C & Country A & Country B & Country C \\
\hline 0.70 & $\begin{array}{l}\text { A } \\
\text { B } \\
\text { C }\end{array}$ & 178.5 & $\begin{array}{r}1.00 \\
178.5\end{array}$ & $\begin{array}{r}1.00 \\
1.00 \\
178.5\end{array}$ & 198.6 & $\begin{array}{r}1.00 \\
198.6\end{array}$ & $\begin{array}{r}0.80 \\
0.80 \\
198.7\end{array}$ \\
\hline 0.90 & $\begin{array}{l}\mathrm{A} \\
\mathrm{B} \\
\mathrm{C}\end{array}$ & 199.3 & $\begin{array}{c}1.00 \\
199.3\end{array}$ & $\begin{array}{r}1.00 \\
1.00 \\
199.3\end{array}$ & 206.2 & $\begin{array}{c}1.00 \\
206.2\end{array}$ & $\begin{array}{c}0.94 \\
0.94 \\
206.3\end{array}$ \\
\hline
\end{tabular}

ronment scale. With the international evaluation on a production environment basis using performance records (GAMenv), breeding values were predicted for each production environment and were transformed to breeding values for each country in the same way as for the TBV described previously. With MACE and GAMcou, breeding values were predicted for each country and were transformed to breeding values for each production environment by weighting PBV for each country by the proportion of herds in each production environment.

Lastly, the proportion of selected animals that were in common among the top 25 based on MACE, GAMcou, or GAMenv international breeding values and the top 25 based on TBV was examined.

\section{RESULTS AND DISCUSSION}

\section{Genetic Parameters}

Genetic variances. Genetic variance of performance in countries was underestimated by 5 to $10 \%$ (Table 2), depending on the method used. The bias was in absolute value largest for GAMcou. Estimated genetic variance was slightly more biased for MACE compared with NAMcou, except for Country B. The NAmcou estimates were always more variable than estimates obtained with GAMcou; the mean SD of estimates from 15 replicates was 10.6 and 9.8 for NAMcou and GAMcou, respectively. Standard deviation of estimated genetic variances was higher for MACE compared with the other 2 methods for the balanced situation (results not shown). The RMSE of genetic variances for countries was highest for Gamcou because of the larger bias, but no general pattern could be detected in the RMSE difference between Namcou and MacE (Table 2).

Underestimation of genetic variance was expected because sire models, used for estimation of variance components, do not account for selection among the dams (Dong et al., 1988). The magnitude of the bias was slightly smaller for MACE and NAMcou, probably because, in both cases, sire variances were estimated within country. Thus, pedigree and observations from only one country at a time was considered, and data on which selection of imported animals had been based were not included. Discarding information on which selection had been based generally leads to biased inferences about genetic parameters (e.g., Schaeffer et al., 1998).

Genetic variance of production environments was underestimated by $12 \%$ (Table 3 ), but estimates were less

Table 2. Bias ${ }^{1}$ and root mean square error (RMSE) for within-country genetic variance (VarG) for balanced and unbalanced distribution of the production environments and 2 levels of genetic correlation $(\mathrm{rG})$ between production environments.

\begin{tabular}{|c|c|c|c|c|c|c|c|c|c|c|c|c|c|}
\hline \multirow[b]{2}{*}{$\mathrm{rG}$} & \multirow{2}{*}{$\begin{array}{l}\text { Estimated } \\
\text { parameter }\end{array}$} & \multicolumn{6}{|c|}{ Bias } & \multicolumn{6}{|c|}{ RMSE } \\
\hline & & $\mathrm{Namcou}^{2}$ & Mace & GaMcou & NAMcou & Mace & Gamcou & Namcou & MACE & Gamcou & Namcou & MACE & Gamcou \\
\hline 0.70 & $\begin{array}{l}\operatorname{VarG}_{\mathrm{A}}{ }^{3} \\
\operatorname{VarG}_{\mathrm{B}} \\
\operatorname{VarG} \mathrm{C}_{\mathrm{C}}\end{array}$ & $\begin{array}{r}-9.7 \\
-5.1 \\
-12.1\end{array}$ & $\begin{array}{r}-14.0 \\
-4.3 \\
-16.3\end{array}$ & $\begin{array}{l}-19.3 \\
-17.1 \\
-21.6\end{array}$ & $\begin{array}{r}-2.7 \\
3.6 \\
-19.1\end{array}$ & $\begin{array}{r}-3.2 \\
13.4 \\
-17.4\end{array}$ & $\begin{array}{r}-9.5 \\
-5.6 \\
-23.6\end{array}$ & $\begin{array}{l}13.2 \\
11.4 \\
17.6\end{array}$ & $\begin{array}{l}16.3 \\
11.8 \\
20.9\end{array}$ & $\begin{array}{l}21.2 \\
19.9 \\
24.9\end{array}$ & $\begin{array}{r}8.7 \\
11.2 \\
20.6\end{array}$ & $\begin{array}{r}9.9 \\
20.2 \\
20.5\end{array}$ & $\begin{array}{l}12.2 \\
11.2 \\
24.9\end{array}$ \\
\hline
\end{tabular}

\footnotetext{
${ }^{1}$ Mean of 15 replicates; $2.0 \leq \mathrm{SE} \leq 4.4$

${ }^{2}$ NAMcou $=$ national evaluation using performance records, MACE $=$ multiple-trait across-country evaluation, and GAMcou $=$ international evaluation across country using performance records.

${ }^{3}$ Subscripts are references to Countries A, B, and C.
} 
Table 3. Bias ${ }^{1}$ and root mean square error (RMSE) for genetic variance (VarG) in 2 production environments for balanced and unbalanced distribution of the production environments across country and 2 levels of genetic correlation (rG) between production environments.

\begin{tabular}{lllllll}
\hline & & \multicolumn{2}{c}{ Bias } & & \multicolumn{2}{c}{ RMSE } \\
\cline { 3 - 4 } \cline { 6 - 7 } rG & $\begin{array}{l}\text { Estimated } \\
\text { parameter }\end{array}$ & Balanced & Unbalanced & & Balanced & Unbalanced \\
\hline \multirow{2}{*}{0.70} & VarG $_{1}^{2}$ & -24.9 & -22.5 & & 26.3 & 23.3 \\
& VarG $_{2}$ & -21.8 & -24.9 & & 22.7 & 26.2 \\
0.90 & VarG $_{1}$ & -24.0 & -23.0 & & 25.0 & 23.8 \\
& VarG $_{2}$ & -25.8 & -23.7 & & 27.1 & 24.7 \\
\hline
\end{tabular}

${ }^{1}$ Mean of 15 replicates; $1.6 \leq \mathrm{SE} \leq 2.3$.

${ }^{2}$ Subscripts refer to environments 1 and 2 .

variable compared with GAMcou estimates of genetic variance (mean $\mathrm{SD}$ of estimates from 15 replicates was 7.5 and 9.8 for Gamenv and GAMcou, respectively). As a result, RMSE was higher for GAMenv estimates of genetic variance for production environments compared with Gamcou estimates for genetic variance for countries. The effect of the level of simulated genetic correlation between production environments was not as large for GAMenv as for GAMcou, especially for the balanced situation.

Similar to GAmcou, estimates for Gamenv were also obtained with a sire model, and an underestimation of the genetic variance could be expected. The lower SD of estimates for GAMenv compared with GAMcou is in line with the notion that the analysis model for GAMenv is closer to the true, simulated model. In addition, the same amount of data was used to estimate fewer parameters for GAMenv, as it was a 2-trait model as opposed to GAMcou, which was a 3-trait model.

Genetic correlations. Genetic correlations between performance in different countries were consistently underestimated with Gamcou (Table 4). The magnitude of the bias in estimated genetic correlations between performance in different countries was higher for MACE than for Gamcou in most cases (Table 4). The bias of genetic correlations estimated with MACE was always negative for the balanced situation, but, for the unbalanced situation, bias was negative only for the correlation between performance in countries $\mathrm{A}$ and $\mathrm{B}$.

Root mean square error of genetic correlations estimated with MACE was higher than RMSE of genetic correlations estimated with GAMcou in the balanced situation (Table 4). The magnitude of the difference in RMSE between both methods was somewhat smaller compared with the difference in bias, which was due to the higher precision of the genetic correlations estimated with MACE (mean SD of estimates from 15 replicates was 0.03 and 0.01 for GAMcou and MACE, respectively). Standard deviation of MACE estimates was especially low for the balanced situation $(<0.008)$.

The true genetic correlation between countries for the balanced situation and the true genetic correlation between countries $A$ and $B\left(\mathrm{rG}_{\mathrm{A}, \mathrm{B}}\right)$ for the unbalanced situation was equal to unity by design. The upper bound of the parameter space for correlations is unity; hence, the distribution of the estimator will be skewed, and a downward bias was to be expected. The true values for $\mathrm{rG}_{\mathrm{A}, \mathrm{C}}$ and $\mathrm{rGB}, \mathrm{C}$ were different from unity for the unbalanced situations with genetic correlation between production environments (Table 1). Gates et al. (1999) reported negative bias in genetic correlation estimates when populations were selected and sires and management groups were confounded. The same phenomenon could be behind the underestimation of $\mathrm{rGA}_{\mathrm{A}, \mathrm{C}}$ and $\mathrm{rGB}, \mathrm{C}$ with GAMcou, as ties between countries were weak as indicated by the low number of bulls $(\mathrm{n}=27)$ with daughters in countries $\mathrm{B}$ or $\mathrm{C}$ and at least one other country.

Genetic correlations between production environments estimated with GAMenv were biased downward

Table 4. Bias ${ }^{1}$ and root mean square error (RMSE) for genetic correlations ( $r G$ ) between countries for balanced and unbalanced distribution of 2 production environments across country and 2 levels of genetic correlation between production environments.

\begin{tabular}{|c|c|c|c|c|c|c|c|c|c|}
\hline \multirow[b]{3}{*}{$\mathrm{rG}$} & \multirow{3}{*}{$\begin{array}{l}\text { Estimated } \\
\text { parameter }\end{array}$} & \multicolumn{4}{|c|}{ Bias } & \multicolumn{4}{|c|}{ RMSE } \\
\hline & & \multicolumn{2}{|c|}{ Balanced } & \multicolumn{2}{|c|}{ Unbalanced } & \multicolumn{2}{|c|}{ Balanced } & \multicolumn{2}{|c|}{ Unbalanced } \\
\hline & & $\mathrm{MACE}^{2}$ & GAMcou & MACE & GaMcou & Mace & GaMcou & MACE & GaMcou \\
\hline 0.70 & $\begin{array}{l}\mathrm{rG}_{\mathrm{A}, \mathrm{B}}{ }^{3} \\
\mathrm{rG}_{\mathrm{A}, \mathrm{C}} \\
\mathrm{rG}_{\mathrm{B}, \mathrm{C}}\end{array}$ & $\begin{array}{l}-0.052 \\
-0.037 \\
-0.062\end{array}$ & $\begin{array}{l}-0.042 \\
-0.026 \\
-0.048\end{array}$ & $\begin{array}{r}-0.071 \\
0.085 \\
0.066\end{array}$ & $\begin{array}{l}-0.069 \\
-0.076 \\
-0.076\end{array}$ & $\begin{array}{l}0.053 \\
0.038 \\
0.062\end{array}$ & $\begin{array}{l}0.049 \\
0.031 \\
0.056\end{array}$ & $\begin{array}{l}0.072 \\
0.089 \\
0.073\end{array}$ & $\begin{array}{l}0.076 \\
0.083 \\
0.106\end{array}$ \\
\hline 0.90 & $\begin{array}{l}\mathrm{rG}_{\mathrm{A}, \mathrm{B}} \\
\mathrm{rG}_{\mathrm{A}, \mathrm{C}} \\
\mathrm{rG}_{\mathrm{B}, \mathrm{C}}\end{array}$ & $\begin{array}{l}-0.044 \\
-0.033 \\
-0.052\end{array}$ & $\begin{array}{l}-0.018 \\
-0.022 \\
-0.028\end{array}$ & $\begin{array}{r}-0.054 \\
0.015 \\
-0.007\end{array}$ & $\begin{array}{l}-0.033 \\
-0.026 \\
-0.042\end{array}$ & $\begin{array}{l}0.044 \\
0.033 \\
0.053\end{array}$ & $\begin{array}{l}0.023 \\
0.027 \\
0.037\end{array}$ & $\begin{array}{l}0.054 \\
0.017 \\
0.013\end{array}$ & $\begin{array}{l}0.037 \\
0.037 \\
0.061\end{array}$ \\
\hline
\end{tabular}

\footnotetext{
${ }^{1}$ Mean of 15 replicates; $\mathrm{SE} \leq 0.019$.

${ }^{2} \mathrm{MACE}=$ multiple-trait across-country evaluation; GAMcou $=$ international evaluation across country using performance records.

${ }^{3}$ Subscripts refer to countries A, B, and C.
} 
Table 5. Bias ${ }^{1}$ and root mean square error (RMSE) for genetic correlations between production environments $\left(\mathrm{rG}_{1,2}\right)$ for a balanced and unbalanced distribution of the production environments across country and 2 levels of genetic correlation (rG) between production environments.

\begin{tabular}{lllllll}
\hline & & \multicolumn{2}{c}{ Bias } & & \multicolumn{2}{c}{ RMSE } \\
rG & $\begin{array}{l}\text { Estimated } \\
\text { parameter }\end{array}$ & Balanced & Unbalanced & & Balanced & Unbalanced \\
\hline 0.70 & $\mathrm{rG}_{1,2}$ & -0.036 & -0.082 & & 0.040 & 0.084 \\
0.90 & $\mathrm{rG}_{1,2}$ & -0.012 & -0.027 & & 0.015 & 0.033 \\
\hline
\end{tabular}

${ }^{1}$ Mean of 15 replicates; $\mathrm{SE} \leq 0.005$.

(Table 5). The bias was larger when the true genetic correlation between production environments was 0.70 . Bias and RMSE of estimated genetic correlations between production environments were smaller than for estimated genetic correlations between countries.

All data on which selection had been based were included for the Gamenv analysis, and, from that point of view, no bias should be expected. However, the genetic correlation between traits (production environments) can change because of selection (Villanueva and Kennedy, 1991), which was only partly accounted for, as no female relationships were considered in the sire model used to estimate (co)variance components. This could cause downward bias of the genetic correlation similarly as for estimates of the genetic variance from a sire model. Bias was largest for the unbalanced case with simulated genetic correlation between production environments equal to 0.70 . In fact, the genetic correlation between TBV in the last generation was only 0.30 for this situation.

\section{Breeding Values}

International breeding values of males predicted with GAMenv had the lowest RMSE, whether they were expressed on country scales (Table 6) or production en- vironment scales (Table 7). Predicted breeding values were largely unbiased, except for the unbalanced situation with low correlation between production environments, and differences in RMSE were mainly due to differences in precision.

When predictions on country basis were of interest, then considering production environments yielded only marginal improvements for the balanced situation (Table 6). Compared with the other 2 methods, RMSE of breeding values predicted with GAMenv were lower for the unbalanced situation with a low correlation between production environments, caused by both smaller bias and increased precision.

When the interest was to rank animals in production environments, breeding values predicted with GAMenv were more accurate than with MACE and GAMcou, especially for low values of the genetic correlation between production environments (Table 7). Both MACE and Gamcou performed similarly, and access to performance records (GAmcou) alone was not an advantage over meta-analysis of national breeding values (MACE). The larger RMSE for the production environment 2 in both unbalanced situations reflects the lower number of animals with observations in this production environment.

The correlation between TBV, either expressed on country or production environment scale, was high (>0.90) for 3 of the 4 situations, which may explain the small differences in RMSE. For the unbalanced situation with low correlation between production environments, TBV on country and production environment scale were less well correlated, and the RMSE differed more between the international evaluation methods.

Levels of RMSE of breeding values for females were similar for the 3 methods except for the unbalanced situation with low correlation between production environments (results not shown). The observed patterns followed closely those for males described previously. Breeding values for females can be decomposed into a

Table 6. Root mean square error of predicted breeding values of males for 3 countries for balanced and unbalanced distribution of 2 production environments. ${ }^{1}$

\begin{tabular}{|c|c|c|c|c|c|c|c|}
\hline \multirow[b]{2}{*}{$\mathrm{rG}$} & \multirow[b]{2}{*}{ Country } & \multicolumn{3}{|c|}{ Balanced } & \multicolumn{3}{|c|}{ Unbalanced } \\
\hline & & Mace & Gamcou & GAMenv $^{2}$ & MACE & Gamcou & GAMenv $^{2}$ \\
\hline \multirow[t]{3}{*}{0.70} & $\mathrm{~A}$ & 5.4 & 5.5 & 5.2 & 10.0 & 7.7 & 6.4 \\
\hline & B & 6.2 & 5.8 & 5.2 & 10.8 & 7.8 & 6.4 \\
\hline & $\mathrm{C}$ & 5.7 & 5.7 & 5.2 & 8.9 & 8.2 & 7.9 \\
\hline \multirow[t]{3}{*}{0.90} & A & 5.9 & 5.9 & 5.3 & 6.7 & 6.1 & 5.9 \\
\hline & B & 5.8 & 5.7 & 5.3 & 6.6 & 6.4 & 5.9 \\
\hline & $\mathrm{C}$ & 5.8 & 5.5 & 5.3 & 6.9 & 6.9 & 6.5 \\
\hline
\end{tabular}

\footnotetext{
${ }^{1} \mathrm{rG}=$ genetic correlation between production environments, MACE = multiple-trait across-country evaluation, GAMcou = international evaluation across country using performance records, and GAMenv = international evaluation across production environments using performance records.

${ }^{2}$ Predicted breeding value on a country's scale was computed based on predicted breeding values for production environment weighted by the distribution of environments across country.
} 
Table 7. Root mean square error of predicted breeding values of males for 2 production environments (Prod Env) for balanced and unbalanced distribution of the Prod Env across country. ${ }^{1}$

\begin{tabular}{|c|c|c|c|c|c|c|c|}
\hline \multirow[b]{2}{*}{$r G$} & \multirow[b]{2}{*}{ Prod Env } & \multicolumn{3}{|c|}{ Balanced } & \multicolumn{3}{|c|}{ Unbalanced } \\
\hline & & $\mathrm{MACE}^{2}$ & GAMcou $^{2}$ & GAMenv & $\mathrm{MACE}^{2}$ & GAMcou $^{2}$ & GAMenv \\
\hline 0.70 & 1 & 7.6 & 7.9 & 6.1 & 10.8 & 8.7 & 6.7 \\
\hline 0.90 & $\begin{array}{l}1 \\
2\end{array}$ & $\begin{array}{l}6.1 \\
6.2\end{array}$ & $\begin{array}{l}6.3 \\
6.4\end{array}$ & $\begin{array}{l}5.8 \\
6.0\end{array}$ & $\begin{array}{l}6.5 \\
7.0\end{array}$ & $\begin{array}{l}6.4 \\
6.9\end{array}$ & $\begin{array}{l}6.0 \\
6.8\end{array}$ \\
\hline
\end{tabular}

${ }^{1} \mathrm{rG}=$ Genetic correlation between Prod Env, MACE = multiple-trait across-country evaluation, GAMcou = international evaluation across country using performance records, GAMenv = international evaluation across Prod Env using performance records.

${ }^{2}$ Predicted breeding value for a Prod Env was computed from predicted breeding values for each country weighted by proportion of herds in each Prod Env in each country.

regression of the contemporary group deviation on the parent average. The magnitude of regression was similar in all 3 models because of the similarity of heritabilities in the 3 models. Variation in parent average was largely determined by sire breeding values because of their higher reliability, explaining why observations about RMSE for males and females were alike.

Balanced; $r G=0.70$

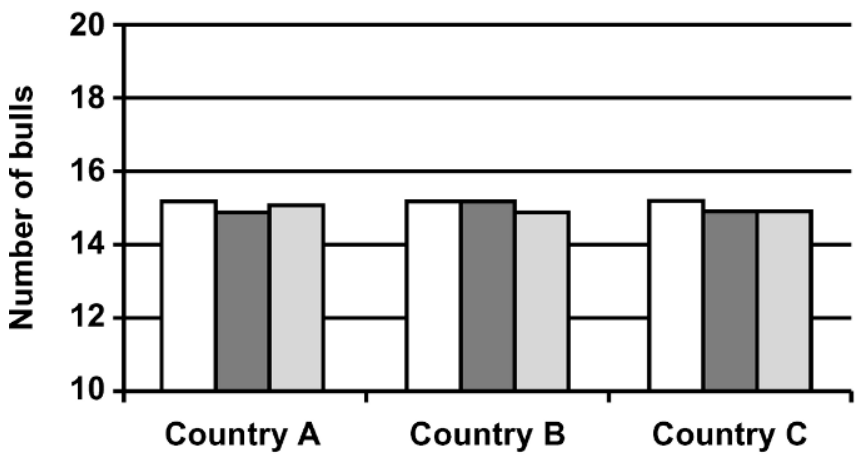

Balanced; $r G=0.90$

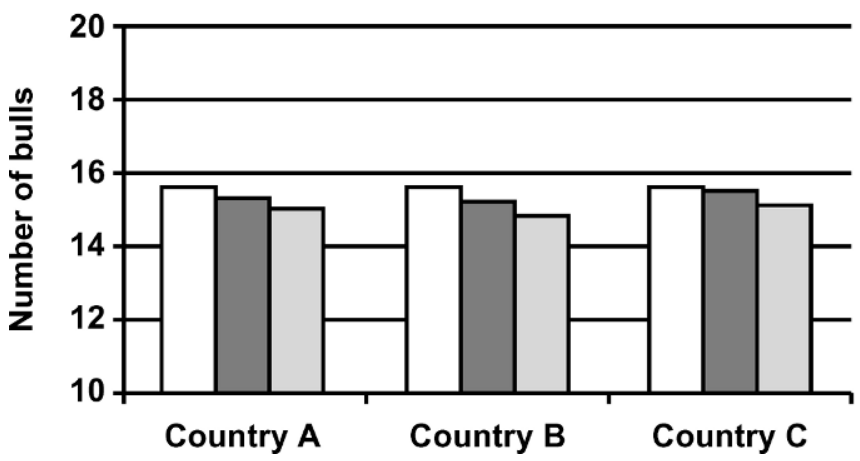

\section{Rankings}

The success of each method in identifying the top bulls differed (Figures 3 and 4), despite the resemblance of RMSE of PBV for males among all 3 methods. Sire rankings on country bases mainly differed for the unbalanced situations (Figure 3); however, sire rankings
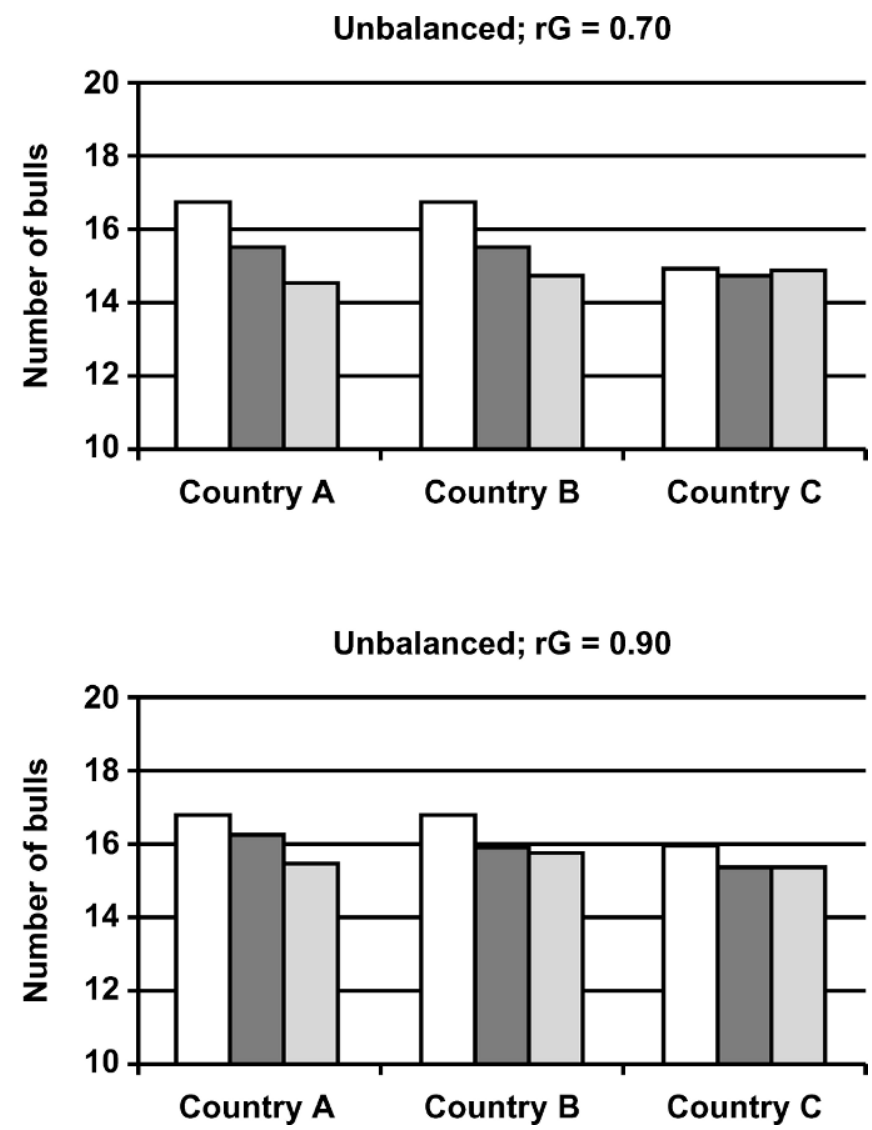

Figure 3. Number of males in the top 25 for predicted breeding values in common with the top 25 for true breeding values in 3 countries for balanced and unbalanced distribution of 2 production environments. GAMenv $(\square)=$ international evaluation on production environment basis using performance records, GAMcou $(\square)=$ international evaluation on country basis using performance records, MACE $(\square)=$ multipletrait across-country evaluation, and $\mathrm{rG}=$ genetic correlation between production environments. 
Balanced; $\mathrm{rG}=\mathbf{0 . 7 0}$

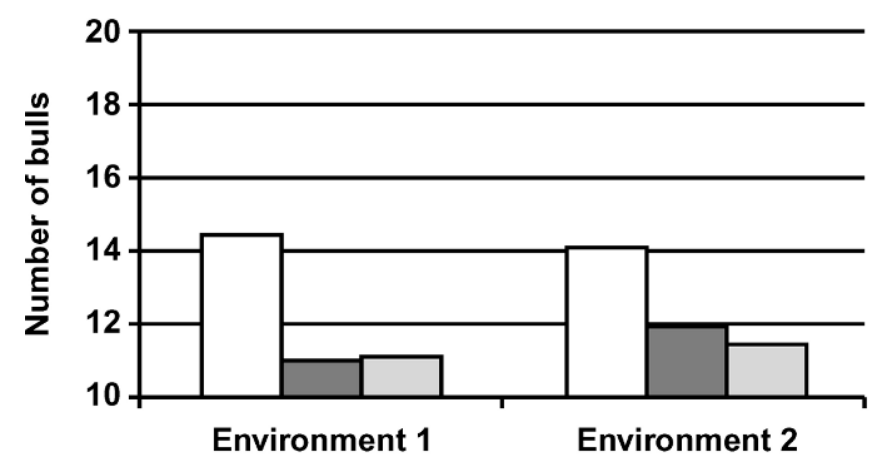

Balanced; $r G=0.90$

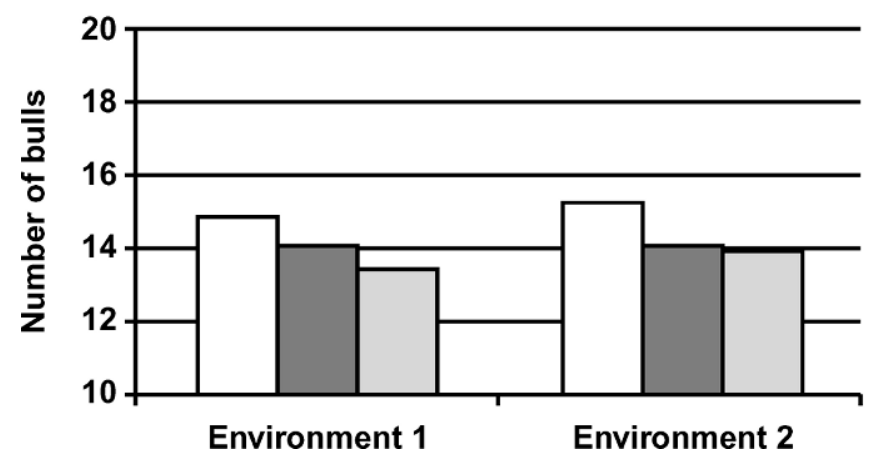

Unbalanced; $\mathrm{rG}=\mathbf{0 . 7 0}$
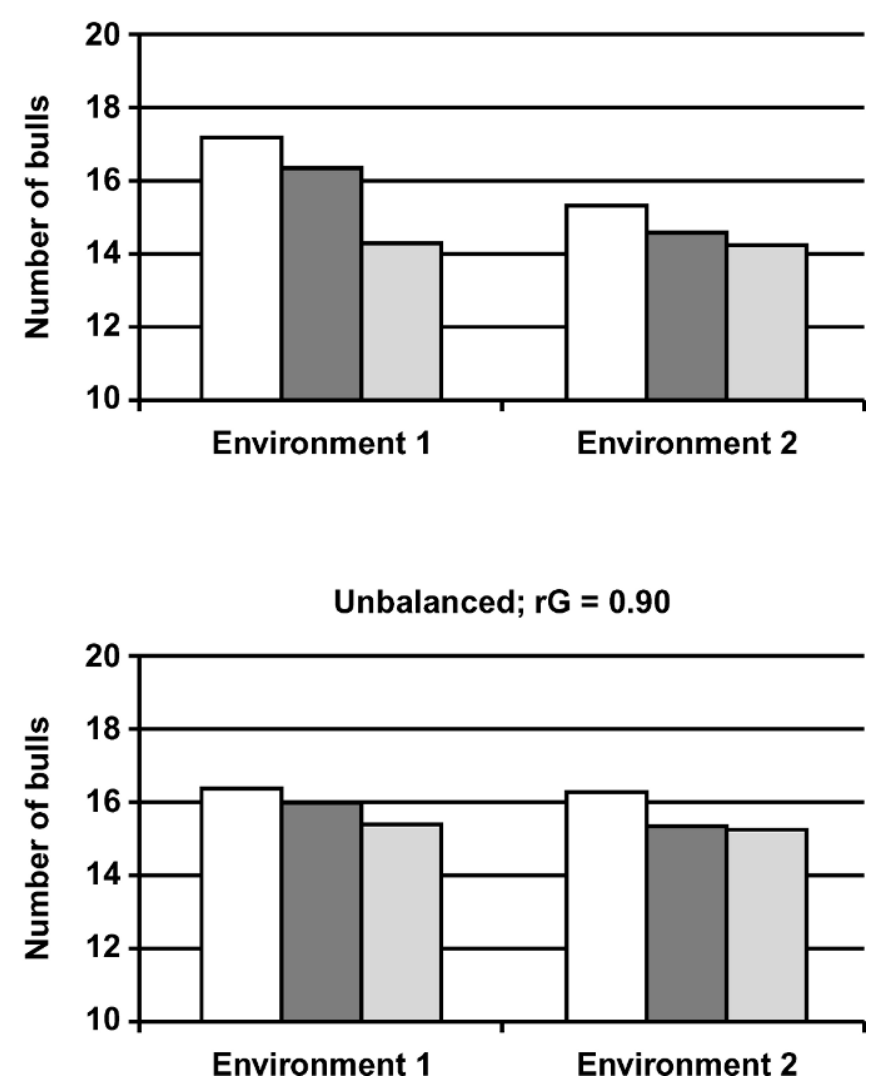

Figure 4. Number of males in the top 25 for predicted breeding values in common with the top 25 for true breeding values in 2 production environments for balanced and unbalanced distribution of the production environments across country. GAMenv $(\square)=$ international evaluation on production environment basis using performance records, GAmcou $(\square)$ = international evaluation on country basis using performance records, MACE $(\square)$ = multiple-trait across-country evaluation, and $\mathrm{rG}=$ genetic correlation between production environments.

on production environment scales mainly differed for the situations with low correlation between production environments (Figure 4). The TBV of the 25 best sires for GAMenv was, on average, between 0.01 and 0.25 genetic standard deviation units higher compared with the other 2 methods, depending on the situation.

\section{General Discussion}

Results from this simulation study indicate bias in estimated genetic parameters. Root mean square error of PBV seemed to be little affected by the bias in genetic parameters and favored the 2 methods that used performance records. The difference between models was more accentuated when the distribution of production environments over countries was unbalanced and the genetic correlation between production environments was low (0.70). The international genetic evaluation that used performance records and considered production environments was most successful at identifying animals with high genetic merit.
The same genetic parameters were assumed in both production environments in the present study, a condition that is not likely met in practice. For example, residual variances and heritabilities have been reported to differ between herds with high and low production level (e.g., Hill et al., 1983; Meuwissen et al., 1996). The use of an average heritability in such cases may over- or underestimate the genetic trend in diverse environments, causing bias in PBV. In addition, the degree of regression of contemporary group deviations toward the parent average will be affected, which may lead to under- or overdispersed PBV and, consequently, to suboptimal rankings of animals.

For the international evaluation across production environment, it was assumed known which production environment each herd belonged to. In practice, however, statistical techniques have to be used for classification of herds, and uncertainty is associated with such procedures. Misclassification of herds probably decreases the differences between the across-production 
environment evaluation and the other 2 methods, but the extent should be evaluated in a sensitivity study.

The statistical models for national and international genetic evaluations were the same in this study. However, in practice, national evaluation models vary widely across country (Interbull, 2000), which would affect estimates of the genetic correlation between countries computed with MACE (Emanuelson et al., 1999). Lohuis and Dekkers (1998) showed that standardization of data collection and genetic evaluation models across countries could lead to increased genetic gains.

Using MACE, national PBV are jointly analyzed with a sire model, and effects of selection and non-random mating are only partially accounted for. As mating between animals was random in the present study, an important advantage of using an animal instead of a sire model for prediction of breeding values, the possibility to account for non-random mating (e.g., Hudson and Schaeffer, 1984), was not exploited. Evidence of non-random mating for milk production and conformation traits have been reported (Hudson and Schaeffer, 1984), and MACE could be expected to perform suboptimally under such conditions. Effects of non-random mating are at least partly accounted for in meta-analysis of national breeding values, as these breeding values are commonly predicted with an animal model (Interbull, 2000). However, in many cases, limited information is available about ancestors of imported bulls, restricting the possibility of the animal model to account for non-random mating. Furthermore, joint analysis of national breeding values using MACE considers only information on male relatives.

\section{CONCLUSIONS}

Management conditions may vary widely in practice, and the results of this simulation study suggest that an international genetic evaluation that uses performance records and considers production environment in the model will result in improved selection decisions if the production environment for each herd is known. The improvement depends on the genetic correlation between performance in different production environments and the distribution of production environments across countries. Situations encountered in practice are more extreme than those considered in this simulation study, probably favoring international evaluations across production environment using performance records. Moreover, differences in statistical models for national genetic evaluations were not a source of variation in this study, but were expected to disadvantage meta-analysis of national breeding values. To take full advantage of improvements in across-production envi- ronment evaluations using performance records, breeding programs should be run on the basis of production environments rather than countries.

\section{ACKNOWLEDGMENTS}

Financial support by the World Guernsey Federation, and the US Department of Agriculture/ Emerging Market Program is gratefully acknowledged.

\section{REFERENCES}

Banos, G., and C. Smith. 1991. Selecting bulls across countries to maximize genetic improvement in dairy cattle. J. Anim. Breed. Genet. 108:174-181.

Banos, G., G. R. Wiggans, and J. A. B. Robinson. 1992. Comparison of methods to rank bulls across countries. J. Dairy Sci. 75:2560-2568.

Dong, M. C., L. D. VanVleck, and G. R. Wiggans. 1988. Effect of relationships on estimation of variance components with an animal model and restricted maximum likelihood. J. Dairy Sci. 71:3047-3052.

Fikse W. F., and G. Banos. 2001. Weighting factors of sire daughter information in international genetic evaluations. J. Dairy Sci. 84:1759-1767.

Emanuelson, U., W. F. Fikse, and G. Banos. 1999. Impact of national genetic evaluation models on international comparisons. Interbull Bull. 20:115-119.

Gates, P., K. Johansson, and B. Danell. 1999. "Quasi-REML" correlation estimates between production and health traits in the presence of selection and confounding. J. Anim. Sci. 77:558-568.

Interbull. 2000. National Genetic Evaluation Programmes for Dairy Production Traits Practice in Interbull Member Countries 19992000. Interbull Bull. 24. International Bull Evaluation Service, Uppsala, Sweden.

Hill, W. G., M. R. Edwards, M. K. A. Ahmed, and R. Thompson. 1983. Heritability of milk yield and composition at different levels and variability of production. Anim. Prod. 36:59-68.

Hudson G. F. S., and L. R. Schaeffer. 1984. Monte Carlo comparison of sire evaluation models in populations subject so selection and nonramdom mating. J. Dairy Sci. 67:1264-1272.

Jairath, L., J. C. M. Dekkers, L. R. Schaeffer, Z. Liu, E. B. Burnside, and B. Kolstad. 1998. Genetic evaluation for herd life. J. Dairy Sci. 81:550-562.

Jensen, J., E. A. Mantysaari, P. Madsen, and R. Thompson. 1997. Residual maximum likelihood estimation of (co)variance components in multivariate mixed linear models using average information. J. Indian Soc. Agric. Stat. 49:215-236.

Lohuis, M. M., and J. C. M. Dekkers. 1998. Merits of borderless evaluations. Proc. 6th World Congr. Genet. Appl. Livest. Prod. 26:169-172. Armidale, Australia. Univ. of New England, Armidale, Australia.

McGuirk, B. 1998. Developments in the dairy cattle breeding industry. Interbull Bull. 19:21-28.

Meuwissen, T. H. E., G. De Jong, and B. Engel. 1996. Joint estimation of breeding values and heterogeneous variances of large data files. J. Dairy Sci. 79:310-316.

Schaeffer, L. R. 1994. Multiple-country comparison of dairy sires. J. Dairy Sci. 77:2671-2678.

Schaeffer, L. R., F. S. Schenkel, and L. A. Fries. 1998. Selection bias on animal model evaluation. Proc. 7th World Congr. Genet. Appl. Livest. Prod. 25:501-508. Montpellier, France. INRA, Toulouse, France.

Sigurdsson, A., G. Banos, and J. Philipsson. 1996. Estimation of genetic (co)variance components for international evaluation of dairy bulls. Acta Agric. Scand. 46:129-136. 
Strandén, I., and M. Lidauer. 1999. Solving large mixed linear model using preconditioned conjugate gradient iteration. J. Dairy Sci. 82:2779-2787.

Sullivan, P. G. 1999. Appendix: REML estimation of heterogeneous sire (co) variances for MACE. Interbull Bull. 22:146-148.

Tier, B., and H. U. Graser. 1991. Predicting breeding values using an implicit representation of the mixed model equations for a multiple trait animal model. J. Anim. Breed. Genet. 108:81-88.
Villaneuva, B., and B. W. Kennedy. 1990. Effect of selection on genetic parameters of correlated traits. Theor. Appl. Genet. 80:746-751.

Weigel, K. A., and R. Rekaya. 2000. A multiple-trait herd cluster model for international dairy sire evaluation. J. Dairy Sci. 83:815-821.

Zwald, N., K. A. Weigel, and R. Rekaya. 2001. Application of a multiple-trait herd cluster model for genetic evaluation of dairy sires from seventeen countries. Interbull Bull. 27:13-18. 